\title{
Galería de asustaniños de carne y hueso. Miedo y fascinación en torno a las categorías de la anormalidad en Andalucía
}

\author{
Flesh-and-Blood Bogeymen Gallery. \\ Fear and Fascination with Abnormality Categories in Andalusia
}

\author{
Alberto del Campo Tejedor \\ Fernando C. Ruiz Morales \\ Universidad Pablo de Olavide, Sevilla
}

\section{RESUMEN}

Una investigación llevada a cabo en Andalucía sobre los asustaniños revela que los menores no solo han temido al Sacamantecas, al Hombre del saco y otros personajes ficticios, sino que sus progenitores utilizaron a individuos de carne y hueso para incitarles a la obediencia, a través del miedo. La producción social de asustaniños reales se asienta sobre la categorización estereotípica de ciertos individuos marginales, bajo unos pocos arquetipos de anormalidad: el borracho, el drogadicto, el delincuente, el loco, la bruja, el gitano, pero también el lisiado, el mendigo, el vagabundo, incluso el vendedor ambulante. Centrándonos en el recuerdo de los que fueron niños entre los años 30 y el final del siglo XX, este trabajo relaciona los discursos sobre estos asustaniños y el universo simbólico en torno a estas categorías de anormales, rastreable en leyendas, cuentos, supersticiones, bulos y otros relatos, entre la ficción y la realidad. Se comprende así cómo se gestan las ambivalentes imágenes sobre quienes sin dejar de ser considerados anómalos, desviados, extraños, monstruosos, pervertidos y peligrosos, luego censurables y temibles, también son cercanos, familiares, y despiertan tanto el rechazo como la curiosidad y la fascinación, viviendo en los márgenes de nuestra cotidianeidad.

Palabras clave: Asustaniños; Andalucía; Anormales; Marginación; Miedo infantil.

\section{SUMMARY}

Research into bogeymen conducted in Andalusia in Spain reveals that children have not only been afraid of the Sacamantecas [Fat-extractor], the Hombre del saco [Sack Man] and other famous fictional characters. Their progenitors have also used real individuals to scare them into obedience. The social production of bogeymen operates through stereotypical categorization of marginalized individuals that fall into 'abnormality' archetypes: the drunkard, the drug addict, the criminal, the madman, the witch and the gypsy, but also the cripple, the beggar, the vagabond and even the peddler. Analysing the memories of those who were children between the 1930s and the end of the 20th century, this paper connects discourse on bogeymen with the symbolic universe regarding the categories of 'abnormal' individuals that appear in legends, stories, superstitions, false rumours and other narratives, spanning the divide between fiction and reality. In the process, we seek to understand the ambivalent images constructed around those who are considered anomalous, deviant, strange, monstrous, perverted and 
dangerous, and therefore censurable and fearsome, but who also are familiar and live on the sidelines of our daily lives, engendering not only rejection, but also curiosity and fascination.

Key words: Bogeymen; Andalusia (Spain); Abnormal; Outsiders; Child Fears.

\section{INTRODUCCIÓN}

Una encuesta, realizada entre los años 2009 y 2011 en poblaciones andaluzas, en la que se pedía información sobre el principal personaje, lugar u objeto que hubiera despertado miedo en la infancia, coronó como rey del terror infantil al Hombre del saco y otros asimilables a él (presentes en 260 de las 689 contestaciones válidas), seguidos del Coco y otros monstruos (157). ${ }^{1}$ Sin embargo, en un número nada desdeñable de respuestas (45), el encuestado identificó al asustaniños como una persona de carne y hueso o, incluso, un colectivo entero. Frente a vampiros, extraterrestres, fantasmas y otros personajes fantásticos, estos asustaniños estaban ahí y eran vistos realmente por los menores. No todos despiertan el rechazo por su peligrosidad, ni siquiera por ser extraños (dado que en muchos casos forman parte del paisaje cotidiano de los niños), sino también por constituirse como moralmente repudiables, lo que se comprobaría no solo en su comportamiento, también en su fisionomía. Por lo general estos asustaniños (que llamaremos reales para diferenciarlos de los fantásticos o ficticios) pertenecen a dos de los tipos que Foucault (2001) incluye en la categoría de anormales: los monstruos y los incorregibles. Para conocer mejor a esos asustaniños reales, emprendimos un trabajo de campo entre los años 2014 y 2015, completando la información de las encuestas con entrevistas semiestructuradas a informantes privilegiados. ${ }^{2}$

Partimos en nuestro estudio de que toda realidad supone una construcción social, por lo tanto simbólica; es decir, todo hecho está tejido por una maraña de significados que se superponen históricamente y se recrean, con sucesivas modificaciones, en cada momento (Berger y Luckmann 1968). El asustaniños se construye bajo una lógica que estereotipa, deforma y envilece al personaje en cuestión, enfatizando su aspecto y comportamiento maligno y tenebroso, con el fin de provocar el miedo en el niño, de tal manera que se someta a las directrices de los adultos. Es así un protagonista involuntario del control social infantil; sus actos y su aspecto son el material del

\footnotetext{
${ }^{1}$ La encuesta fue realizada por profesores de las universidades de Málaga, Sevilla y Pablo de Olavide (Sevilla), en el marco de un proyecto sobre cultura oral en el que se contó con la colaboración de varios alumnos. Aunque se ejecutó en todas las provincias andaluzas, el trabajo fue más incisivo en las de Málaga y Sevilla. Dividida en 25 ítems, la encuesta preguntaba por el asustaniños principal de la infancia, de tal manera que el encuestado le describiera, identificando su hábitat, el origen de la amenaza y otras variables que permitieran un retrato del asustaniños, amén de otros datos para su contextualización, como las situaciones y lugares de transmisión oral. Los primeros resultados, tomando en consideración una muestra de 420 cuestionarios, se orientaron hacia el establecimiento de una tipología de asustaniños y su relación con la variable edad (Hijano, Lasso y Ruiz 2011). Aprovechamos para agradecer al profesor M. Hijano su inestimable colaboración.

${ }^{2}$ Esta segunda fase (2014-2015), a cargo de los autores de este artículo, se llevó a cabo sobre todo en la provincia de Sevilla.
} 
que se moldea su imagen, pero su específica categorización no depende tanto de lo que haga o deje de hacer, sino de que dichos comportamientos sean susceptibles de encajar dentro de alguna de las categorías de anormales. Ello implica, por lo tanto, un discurso sobre un sujeto en cuanto arquetipo de anormalidad, realizado y puesto en escena generalmente por los adultos, para el niño, con el fin de provocar su miedo y suscitar la obediencia a unas normas. Llamaremos asustador al que crea o transmite el relato sobre los asustaniños delante de un menor, que es el asustado. Dicho relato suele escenificarse con buenas dosis de dramaturgia, para provocar un efecto sensitivo duradero, por lo que parece adecuado llamarlo performance asustadora. El asustaniños, por su parte, es el asunto del mensaje al que se refiere la performance asustadora, aunque en ocasiones se convierte también en actor, dado que el menor puede interaccionar con él.

En la producción social de los asustaniños confluyen las experiencias particulares de las personas que tratan con el personaje en cuestión (especialmente los asustadores y los asustados), pero también los discursos e imágenes que se han ido sedimentando históricamente en torno a dichos arquetipos de anormalidad. El asustaniños actúa como una perfecta encarnación de una categoría, un tipo de persona históricamente construido con significados negativos, y que ejemplifica lo anormal y lo desviado, aquello que debe ser controlado con la intervención de múltiples sujetos y relaciones de dominación, más allá del Estado (Foucault 1978: 157). La ecuación de que $x$ (un individuo en concreto) es un tipo de $y$ (una categoría arquetípica de anormalidad) es un proceso que va más allá de su construcción como asustaniños, y tiene que ver con el poder de normalización (Foucault 2001: 47) que opera en diversos contextos. De hecho, la producción social de los asustaniños toma discursos e imágenes que encontramos en leyendas, cuentos, habladurías, refranes, creencias populares, películas, medios de comunicación, así como en relatos más o menos sanguinolentos que habitan en la memoria sobre el carácter de tal o cual tipo de personas, o incluso en las descripciones de los asustaniños ficticios: monstruos devoraniños y otros seres fantásticos.

Nuestro propósito principal es relacionar los individuos de carne y hueso que se convirtieron en asustaniños con las categorías de anormales que encarnan, centrándonos principalmente en la experiencia de los que fueron presa del miedo cuando eran niños, es decir los asustados. Con ello pretendemos dar a conocer un tipo de tecnología de la anomalía bumana (Foucault 2001: 62) en un contexto poco estudiado. La producción social de asustaniños implica, desde el punto de vista foucaultiano, una de las formas de saber (a través de presupuestos estereotípicos sobre ciertos tipos de personas), de poder (bajo la autoridad y legitimidad paternal) y de subjetividad (o de interiorización de dichos conjuntos de personas como esencialmente despreciables y peligrosos). El asustaniños no muestra tanto lo que el asustador cree sobre un individuo en concreto, sino lo que la sociedad da por supuesto sobre un determinado tipo de gente, que el asustaniños ejemplifica inmerso en un relato tan fácilmente digerible por el niño, como impactante.

Sin embargo, el miedo y el rechazo no son los únicos sentimientos que suscitan estos personajes. Como en los adultos, en el niño se despierta también la curiosidad, incluso la fascinación, de tal manera que es posible rastrear desde temprana edad los sentimientos contradictorios y ambiguos que desatan en la edad adulta los seres 
anormales, y más en concreto los etiquetados como peligrosos. Ni el miedo ni el asombro pertenecen por completo al mundo racional, de ahí que el proceso foucaultiano de construcción de los arquetipos malvados y desviados no sea nunca cerrado ni susceptible de ser dirigido del todo por el poder. Así, los asustaniños reales muestran en el fondo la ambivalencia con que el mundo adulto acoge lo diferente, lo imprevisible, lo inseguro, incluso lo sorpresivo y contradictorio; aquello que, sin pertenecer a otro mundo, no deja de estar en los márgenes de nuestra propia existencia, aquello que, siendo anómalo, forma parte de nuestra cotidianeidad.

\section{MENDIGOS, VAGABUNDOS, INDIGENTES: EL HOMBRE DEL SACO}

El hogar, como espacio privado y lugar de residencia y convivencia de la familia nuclear, ha sido y sigue siendo uno de los elementos esenciales de la normalidad, rasgo imprescindible de nuestra carta de ciudadanía, frente a aquellos que no quieren o no pueden vivir en un lugar estable. La residencia fija somete al individuo al control, tanto del vecindario y la comunidad que ejerce un informal escrutinio de sus movimientos y sus actos, como del poder político, que le sitúa bajo una concreta jurisdicción. Así, desde antiguo, los nómadas de todo tipo, incluyendo los feriantes, han sufrido una secular desconsideración.

Cierto tipo de gente callejera e itinerante, como los vagabundos, mendigos e indigentes, han constituido categorías ambivalentes, porque si por un lado su exposición a los peligros de la calle y su pobreza habrían de despertar la caridad cristiana, por otro han estado vinculados al mundo del hampa y la picaresca (como tantas veces recreó la literatura del Siglo de Oro con los falsos ciegos y mendigos), cuando no directamente a la criminalidad. Por otra parte, la vida en la calle ha sido sinónimo de libertad, incluso de diversión e inversión de roles dentro la cultura cómica popular de raíz carnavalesca (Bajtin 1995); pero también el sometimiento del espacio público a la normalización urbanística y social, ha generado espacios intersticiales y degradados (solares vacíos, por ejemplo), última morada de las capas más marginales de la sociedad: los indigentes.

Algunos de estos outsiders callejeros fueron convertidos en asustaniños, por mor de los relatos de madres y otros familiares que querían, sobre todo, impedir que sus hijos se mezclaran con extraños que vivían al margen de las convenciones sociales. Uno de estos buscavidas errantes fue conocido en Cantoria (Almería) en los años 70 como Andrés el de la guitarra. Sus pintorescas maneras, incluyendo su singular atuendo, suscitaban sentimientos de inseguridad y miedo en los niños, que no podían identificarle con una imagen familiar. Una mujer le recuerda así: "Era un hombre extraño; un vagabundo con una larga barba, pelo enmarañado. Iba vestido como un mejicano: gran sombrero, un poncho y una guitarra colgada". Andrés visitaba el pueblo todos los inviernos y pedía limosna "de puerta en puerta", cobijándose de noche en cualquier portal. Los mismos niños que de pequeño le temían, fueron viendo, según crecían, que resultaba en verdad inofensivo, como indica esta misma informante:

Forma parte de esa galería de personajes siniestros que atemorizaban en nuestra infancia. Con el tiempo lo recuerdo con ternura pues era solo un simple indigente, que de cuando en cuando amenizaba con su presencia la monotonía del pequeño pueblo. 
García Lorca (1969: 98), interesado en las nanas y en la imaginación infantil, supo ver que los niños veían como cocos a aquello que encontraban extravagante, especialmente si encerraba una especial fuerza expresiva. Rasgo inequívoco de muchos asustaniños es un aspecto externo que no se corresponde con el que lucen los padres (referentes de normalidad y seguridad), bien por su andrajoso atuendo, bien porque resulta extraño y desconocido. Así, por ejemplo, en Aznalcóllar (Sevilla) las madres recurrían en los años 80 al Brujo, un individuo solitario, de aspecto siniestro y vestimenta estrafalaria. El desaliño, la larga barba, cuando no la explícita suciedad, son rasgos inequívocos de estos asustaniños. En ese sentido, las descripciones de asustaniños de carne y hueso como el Brujo o Andrés el de la guitarra no son muy diferentes de las de otros personajes ficticios, que eran presentados como mendigos y vagabundos. Uno de los arquetipos de asustaniños ficticios más extendido en Andalucía es el Canco, que los informantes de ciertos pueblos de Cádiz o Málaga ${ }^{3}$ interpretan como un "mendigo sucio" o un "vagabundo viejo". En ocasiones, pobres de solemnidad, mendigos y otros sujetos reales que vivían en la indigencia, se convirtieron en excelentes asustaniños, ya que los menores podían ver sus degradadas fachas en la calle. Es el caso de Bartolo en El Viso del Alcor (Sevilla) durante los años 7080 , nombrado frecuentemente por madres y tías para que los niños no estuvieran demasiado tiempo en los espacios de todos y de nadie.

Los mendigos que llevaban sus pertenencias en un saco o en un zurrón, fueron fácilmente asimilados al Hombre del saco, especialmente si se mostraban huraños, esquivos, "desaliñados", como este Bartolo, que vivía en la calle en la más absoluta indigencia. Los niños pensaban que el tal Bartolo podría raptarlos en cualquier momento, introduciéndolos en el saco, donde quién sabe si llevaba alguna prenda personal de su última víctima infantil, al igual que hacían ciertos mendigos ficticios, como el Canco. No solo los mendigos se asociaron a alguna de las variantes del Hombre del saco; también ciertos oficios como el de trapero, gente, por lo general, de muy baja estofa, que compraba o, más frecuentemente, intercambiaba diversos productos por ropa vieja. Los sonoros pregones de los traperos para anunciarse,${ }^{4}$ así como el llevar un gran saco a cuestas donde metían la ropa, sirvieron para alentar la imaginación. Un sevillano recuerda así sus miedos infantiles, retrotrayéndose a mediados del siglo XX:

Había un trapero que vivía debajo de casa y que mi madre me asustaba con él. Ella me decía: 'Si no comes o eres malo, van a venir los mantequeros y te van a sacar la manteca del cuerpo'. A mi vecino el trapero lo veíamos como un demonio (Santos y Blanco 1996: 250).

Otros traperos eran imaginarios, aunque inspirados en hombres que desempeñaban ese oficio. En Sevilla se asustaba a los niños en los años 50 con el Trapero, un supuesto ladrón barbudo y sucio que aparecía por el barrio para quitar la ropa a los niños. No extraña que asustaniños reales y ficticios convivan juntos en la memoria de quienes los sufrieron en la infancia, especialmente si los personajes de carne y

\footnotetext{
${ }^{3}$ Nos referimos siempre al lugar donde residían los informantes en su infancia, no a su nacimiento ni a su residencia actual.

${ }^{4}$ Uno de ellos pregonaba por tierras granadinas: "Buscar por los rincones / que crían chinches y ratones. / ¡El traperooooooooooo!” (según nos cuentan en entrevista realizada en Granada capital a varón de 70 años).
} 
hueso eran capaces de suscitar paralelismos con el Hombre del saco. El 38\% de los encuestados aludieron a este, o a alguna otra figura imaginaria que presuntamente se dedicaba a raptar niños metiéndolos en un saco para después matarlos, extrayéndoles la sangre o la grasa: Tío del saco, Mantequero, Sacamantecas, Chupasangre, Sacasangre, Tío del zurrón, Señor mantecoso, Tío manteca, Tío sainero, Tío cazasebos, etc. Es probable que estas figuras fantásticas se retroalimentaran con la interacción con individuos vagabundos, que llevaban sus pertenencias efectivamente en un zurrón o en un macuto, y que aparecían por los pueblos para pedir limosna o para ganarse la vida con pequeñas compraventas o servicios. El caso de los ropavejeros es paradigmático. Hemos encontrado varias localidades (como Constantina, en Sevi1la) en las que el hombre al que todos conocían como el Ropavejero se convirtió, de hecho, en asustaniños.

\section{VENDEDORES AMBULANTES}

Los singulares atuendos de algunos vendedores ambulantes, con sus exóticas mercancías, explican también que algunos adquirieran el estatus de asustaniños. Estos tuvieron desde antiguo un papel ambivalente porque, si bien despertaban cierta fascinación, al provenir de lugares lejanos (como indicaban tanto su indumentaria como sus productos), por otra parte eran vistos con recelo, como ha demostrado Fontaine (1993). El buhonero, y en general el vendedor ambulante, ofrece productos que escapan al control del fisco; sobre su mercancía recae siempre la sospecha de que es de dudosa procedencia; además, su carácter itinerante impide ulteriores reclamaciones en caso de insatisfacción, lo que ha permitido todo tipo de fraudes. Por otra parte, sus pregones y otras técnicas de venta de índole performativa, les vinculaba a los charlatanes, y aun a otros oficios menos honrosos que tenían en la calle y la plaza su contexto principal: saltimbanquis, titiriteros, ciegos recitadores y vendedores de jácaras y romances. Durante siglos, los escalafones más bajos de la sociedad se dedicaron a la venta ambulante: moriscos, gitanos, pero también emigrantes extranjeros (franceses, típicamente auverneses y lemosinos) y nacionales de las zonas más pobres: Galicia, Asturias, Cantabria.

Así, pues, el vendedor ambulante no ha gozado precisamente de buena reputación. Asociado al foráneo, a la estafa, cuando no directamente al vagabundaje y la mala vida, encarnó al extraño, al otro, idea que nunca desapareció del todo, incluso cuando el costumbrismo decimonónico lo elevó a tipo popular. Naturalmente, su estatus dependía de los servicios que ofrecía o los bienes que vendía. Algunos de estos productos, considerados viles y sucios, manchaban también a los vendedores con un particular estigma. Así, durante siglos, mondongueras, pescaderas, curtidores o los mencionados traperos han sido considerados impuros.

Entre el elenco de asustaniños que se ganaban la vida en la calle en Andalucía, están individuos como el Carbonerillo, un sujeto sevillano que vendía carbón en los años 50, de la misma manera que hacía el célebre cantaor del mismo nombre. Este Carbonerillo es recordado como un hombre "con gran bigote, tiznado de carbón, mal vestido", que gustaba de asustar a los niños con petardos, tal vez harto de que estos se burlaran de él, tal y como ocurría con otros vendedores callejeros. A los ojos de 
un niño, la cara tiznada de negro convertía al Carbonerillo en un ser siniestro y zozobrante, especie de Coco u otro personaje negrestino. No es el único vendedor callejero que asustaba a los niños. Hay a quien se le atemorizaba en la Sevilla de la postguerra con los jaboneros (Santos y Blanco 1996: 306), mientras que en otros lugares resultaban intrigantes los quincalleros o los caldereros.

En un estudio, actualmente en marcha, sobre los vendedores ambulantes y sus pregones, ${ }^{5}$ nos ha sido dado a conocer cuán frecuentemente estos han despertado el resquemor entre los niños, los cuales han sentido una ambigua atracción, ora intentando no toparse con ellos, ora tentando la suerte con burlas y afrentas de todo tipo, para escapar corriendo. En ocasiones, lo que provocaba el miedo del niño eran los pregones que se lanzaban al aire, especialmente en horas intempestivas en las que el niño dormía.

No extraña, por lo tanto, que entre los asustañiños reales encontremos bastantes vendedores callejeros. Así, en los años 90, los chiquillos se asustaban en Olvera (Cádiz) con el Ñoño, "un hombre que era pobre e iba con un carro por la calle con cosas que cogía de la basura y los niños de 10 a 12 años le decían cosas y él salía detrás con el carro". De algunos de estos tipos, no se recuerda si eran reales o inventados, dado que padres y madres recurrían indistintamente a figuras ficticias o verdaderas para mantener a sus pupilos bajo control.

\section{BANDOLEROS, ASESINOS Y DELINCUENTES: DE PERNALES AL LUTE}

Si pobres, vagabundos, mendigos y vendedores callejeros podían resultar relativamente inofensivos, no faltan en el repertorio de asustaniños diferentes delincuentes y criminales. Estos han despertado particularmente en Andalucía unos sentimientos contradictorios, entre el rechazo y la admiración, como bien supo ver Caro Baroja (1990: 249-260) al analizar algunos de los romances que exaltaban sus hazañas. Desde el Siglo de Oro, el valiente y el jaque han sido arquetipos que parecen haber echado raíces especialmente en tierras del sur, y más singularmente en Sevilla, como demuestran las innumerables referencias de Quevedo, Cervantes, Quiñones de Benavente y otros escritores (Del Campo y Cáceres 2013: 93-120). Basta leer, por ejemplo, los romances germanescos, escritos en los siglos XVI y XVII con el argot propio de los bajos fondos, cuyos protagonistas, presentados a veces como héroes, son frecuentemente hampones y rufianes sevillanos o que tienen en la capital hispalense su principal lugar de fechorías. Ejemplo es el célebre Escarramán (Di Pinto 2005), un ladrón de capas achulado que acaso existiera realmente, y que, popularizado entre otros por Quevedo, dio nombre a un baile licencioso y a un juego de cartas.

Más tarde, cuando el romanticismo elevó al bandolero andaluz a tipo costumbrista, los viajeros extranjeros pudieron comprobar que, entre las clases bajas, algunos de ellos eran considerados auténticos héroes, lo que pervivió en el siglo XX. Para convertirlos en asustaniños, los familiares solo tenían que exagerar el aspecto negativo y cruel de estos delincuentes, obviando su lectura romántica. Así, presentados como

\footnotetext{
5 Proyecto de investigación "El arte de los vendedores ambulantes andaluces", a cargo de Alberto del Campo y Rafael Cáceres (2011-2014).
} 
despiadados ladrones y asesinos, lograban amedrentar a sus hijos. Es el caso de Francisco Ríos González, más conocido como Pernales, que convertido en asustaniños, es recordado como "una persona muy alta, vestida de bandolero y montado a caballo" (joven de Linares, Jaén). Nacido en Estepa en 1879, protagonizó innumerables robos en los cortijos andaluces, hasta que fue abatido por la guardia civil el 31 de agosto de 1907. A su muerte, el pueblo lo elevó a mito, como a otros bandoleros, y no faltan las coplas ("Ya mataron a Pernales, / ladrón de Andalucía, / el que a los ricos robaba / y a los pobres socorría") y los romances que cantan sus hazañas (Pérez Köhler 2006: 210-215). El recuerdo del bandido perduró durante años. Prueba es que durante mucho tiempo, los habitantes de Villaverde de Guadalimar (Albacete) fueron muy mal considerados en los vecinos pueblos de Jaén, que les acusaban de haber delatado a aquel Robin Hood andaluz. En todo caso, el bandido habría de prestar un último servicio: como asustaniños, los adultos adornaban truculentamente la historia de aquel bandolero, recogiendo alguno de los relatos que sobre él circulaban, como los que le tildaban de violador o de cruel maltratador de su mujer e hijas, a las que habría llegado a quemar por no soportar su llanto. El anterior informante de Linares reconoce, no obstante, que no solo experimentó miedo, sino también "emoción y admiración", dado que "repartía lo que robaba con los pobres".

Así, ciertos criminales facilitaban a las madres y a otros parientes, un recurso perfecto para crear sus asustaniños. En los años 60 y 70 sirvió como tal el último de los delincuentes que aún despertó esa ambivalente impresión, heredera del tiempo de los valientes, truhanes, bandoleros y bandidos: Eleuterio Sánchez, el Lute. Sus fechorías y evasiones fueron portada en los periódicos y primera plana de los noticiarios en toda España. En las encuestas realizadas encontramos el temor al Lute en lugares tan distantes como Dos Hermanas (Sevilla) o Albox (Almería), donde alguna informante se lo imaginaba "grande y feo". A diferencia de la mayoría de asustaniños reales, la imagen de este no provenía de un verdadero contacto, sino de los medios de comunicación y, sobre todo, de los relatos de los asustadores, quienes ponían énfasis en la maldad del Lute, que "podía llevarse a los niños". Como en el caso de Pernales, el Lute despertó la romántica fascinación: no tanto porque lograra estudiar Derecho en la cárcel y escribiera varios libros autobiográficos, sino por sus rocambolescas huidas, como la protagonizada al saltar desde un tren durante un traslado penitenciario, o la que llevó a cabo en la Nochevieja de 1970, al escapar del penal del Puerto de Santa María (Cádiz). Detenido de nuevo en 1973, salió definitivamente en 1981. Fueron aquellos años de evasiones y encarcelamientos los que le convirtieron en figura mítica, y también, inserto en los relatos truculentos de los asustadores, en el terror de algunos niños.

Cuando quien supuestamente comete un crimen es una mujer, esta es identificada a menudo como bruja. Es el caso de la Tía de la maza, que hacía temblar a las niñas de Almogía (Málaga) en los años 60-70: "parecía una bruja, siempre iba de negro", recuerda quien estuviera convencida en su día de que dicha bruja secuestraba a los niños y los asesinaba a golpes, con una maza. Las madres aderezaban la imagen de la Tía de la maza con historias espeluznantes: se decía que había matado y enterrado a sus propios hijos, y que cuando la descubrieron, fue atada a un árbol, sin comida ni bebida, lo que provocaba en los niños una mezcla de temor y lástima, según nos cuentan. 
En la cultura popular existe una clara propensión a introducir en torno a asesinos, violadores y otros criminales, todo tipo de relatos delirantes y fantásticos. Son numerosas las leyendas urbanas que ven en tal o cual crimen una conspiración de Estado, un ritual satánico o cualquier otra interpretación que añada un plus de morbo y espectacularidad al delito. El criminal se convierte fácilmente en psicópata, perturbado, ocultista o miembro de la más rara de las sectas. Así, por ejemplo, de Miguel Ricart, uno de los dos asesinos de las niñas de Alcácer, ${ }^{6}$ se afirma que pertenecía a un insólito culto satánico de Brasil, mientras que han proliferado las historias, a las que se ha dado crédito en publicaciones diversas, acerca de extraños vínculos de este caso y otros sucesos, incluido el cese en su día del periodista Pepe Navarro y su fichaje por otra cadena televisiva. El otro presunto autor, Antonio Anglés, cuyo paradero nunca fue conocido, protagonizó durante años rumores y leyendas que le situaban en tal o cual ciudad o pueblo, lo que despertaba el temor de los niños, sin que los adultos restaran en ocasiones credibilidad a esos rumores.

\section{DEL BORRACHO AL DROGADICTO}

Los viajeros extranjeros entre los siglos XVIII y XIX destacaron muchas veces que, aunque el consumo de alcohol (especialmente de vino) estaba muy arraigado entre todas las capas sociales, eran escasas, en comparación con sus países de origen, las ocasiones en las que se toparon con hombres ebrios. H. James Rose (1841-1878) comparaba en uno de sus libros el carácter del minero andaluz con el del inglés. A pesar de que aquel comenzaba invariablemente la mañana con una copa de aguardiente (como es común aún en muchos lugares de Andalucía), eran raros los borrachos (Rose 2012: 106-107, 159), algo que llamó la atención de otros viajeros, atraídos por la cultura del vino en Andalucía (Fernández e Isla 2012).

El borracho, como sujeto dependiente del alcohol y en reiterado si no constante estado de embriaguez, ha constituido un arquetipo contrario a la hombría, en una cultura en la que el saber beber es parte integral del modelo de masculinidad (Cantero 2003: 60). En muchos lugares es tomado con singular desdén; no tanto se le teme, sino que se le desprecia. Es asunto de padres y madres evitar que el niño y el adolescente entren en contacto con él, dado que, como ocurre con el vago, o el cobarde, el borracho no cumple con los roles de la masculinidad tradicional. El borracho contamina al poner en riesgo la adecuada socialización del niño. Los familiares lo utilizan como ejemplo de desorden físico (pues suele ir desaliñado) y moral (dado que, en su embriaguez, desafía todas las convenciones del decoro). Particularmente a las hijas hay que prevenirlas, dado que en el borracho están incontroladas las fuerzas del macho, que en el hombre hecho y derecho permanecen bajo control: el deseo sexual masculino, interpretado como irrefrenable impulso animal, se convertiría en el borracho en lascivia. Nublada la razón por el alcohol, su comportamiento es imprevisible, por lo tanto peligroso. Así pues, el borracho ha servido como asustaniños para los menores de ambos sexos. En Málaga, por ejemplo, vivía en los años 70 un

${ }^{6}$ El secuestro, violación, tortura y posterior asesinato en 1992 de tres niñas de Alcácer, que tenían entre 13 y 15 años, conmocionó a la opinión pública durante años. 
hombre abandonado por su familia, al que todos conocían como el Guitarrón; "mal vestido, mal encarado" y siempre "de mal humor con los niños", amenazaba con gestos que se recuerdan atemorizantes.

En los años 80, el borracho deja paso a otro arquetipo de marginal patológico y desviado: el drogadicto. El nuevo peligro social, encarnado en el heroinómano, actúa en el imaginario social provocando representaciones de rechazo, pero también de miedo, especialmente por cuanto la drogodependencia impulsa al heroinómano a la violencia para conseguir su dosis, y además por el pánico que suscitó en su día la transmisión del sida. Surgen, entonces, leyendas urbanas sobre tipos que atracan farmacias con jeringuillas infectadas, u otros que amenazan a los jóvenes con transmitirles el VIH si no hacen exactamente lo que les piden. En los barrios suburbiales, como el Polígono San Pablo en Sevilla, los jóvenes relatan sucesos entre la realidad y la imaginación. A los más pequeños se les atemoriza con algún individuo concreto, que pulula por las calles demacrado, o que se ve tirado en cualquier esquina, después de inyectarse su dosis. Son los años en los que el sida se convierte en la nueva peste bíblica, tras su primera detección en 1980, y sus portadores padecen el "doble estigma" (Kowalewski 1988) pues además de enfermos, son drogadictos, homosexuales, indigentes, a veces gitanos.

No solo en los suburbios, también en los pueblos los toxicómanos son tomados como asustaniños. En Fernán Núñez (Córdoba), los niños que tenían entre 4 y 8 años en los 80, recuerdan a un individuo conocido con el elocuente nombre del Cipri malo. Un informante lo rememora hoy como un "tío sucio, con cara de malo y drogadicto". Su sempiterna presencia en la localidad permitía a las madres y abuelas utilizarle como asustaniños, cuando los menores querían ir solos a jugar a la calle o la feria del pueblo; el Cipri malo aprovecharía para secuestrarlos o infligirles distintos daños físicos, lo que resultaba verosímil a todas luces para los niños, dado el aspecto degradado del toxicómano, y la ignorancia de los infantes sobre las consecuencias de ciertas drogas. El progresivo declive del consumo de heroína en ambientes marginales durante las décadas posteriores, difuminó la presencia de los asustaniños drogadictos.

\section{LOCOS}

El loco ha constituido, desde antiguo, una categoría polisémica y ambigua (Foucault 1967; Mitre 2004: 73-84). Por una parte, la locura se ha asociado al desorden y la falta de juicio, al pecado, incluso al hereje, al diablo, al hechicero, al sodomita. Por otra, el cristianismo alentó también la idea de la locura santa por Cristo o la inocencia infantil del loco y el desvalido, privado de culpa. Durante la Edad Media, el fol fue tanto el perturbado como el bufón (que desplegaba una forma jocosa de decir las verdades), y en siglos posteriores se mantuvo esta ambivalencia del loco, incluso cuando se crearon los primeros manicomios, dado que la propia ciencia distinguía entre locos furiosos y locos melancólicos: los primeros peligrosos, los segundos inofensivos, si acaso risibles por sus extravagancias y desvaríos graciosos. Ejemplos de la ambigüedad de la locura y de sus múltiples funciones simbólicas son obras como Elogio de la Locura de Erasmo de Rotterdam o el más universal de nuestros locos, Don Quijote, sin olvidar las diferentes versiones de las fiestas de locos (festa stultorum) y otras prácticas carnavalescas invernales (Del Campo 2008). 
A nivel popular, el loco es simplemente quien se aparta de ciertas convenciones sociales, especialmente las maneras institucionalizadas de presentación y comportamiento en público, sin que se excluya aquí una relación con la creatividad, incluso la genialidad. Sin embargo, después de lo que Foucault (1967) describió como el "gran encierro", el loco es también el enfermo peligroso que requiere su internamiento. El desarrollo de la psiquiatría, con la creación de innumerables patologías psicomédicas, velará por la bigiene pública. La locura será a la vez patología y peligro, que la ciencia aspira a diagnosticar y curar, aunque también codificará como "incurables" algunas prácticas asociadas a la locura. El loco se convierte así en un "degenerado"; el crimen es propio de locos, y muchos locos tienden invariablemente al crimen. Igual que la cárcel, su internamiento en manicomios aleja la peligrosidad, y procura su curación.

No son estos, sin embargo, los locos que aparecen mayoritariamente como asustaniños. Como loco puede designarse en cada pueblo a diferentes seres con circunstancias muy variadas, aunque todas tienen en común su marginalidad: son solitarios, sucios, frecuentemente pobres, estrafalarios, aunque no siempre son peligrosos, mucho menos criminales. Para convertirlos en asustaniños, se requiere mezclar la realidad con sucesos fantásticos. En los años 40, las madres instaban a los niños de Dos Hermanas (Sevilla) a huir de Ismael, un hombre "grande, solitario, loco y sucio", que vivía detrás de la iglesia. Es el lunático, el loco inocente y extravagante a los ojos de los adultos, que lo convierten, para asustar a los niños, en loco furioso. En los 60, otro demente tomó el lugar del miedo infantil en ese pueblo: el Loco de la gangrena, un hombre "arrugado, encorvado y viejo, con la cara desfigurada por un cáncer". Se decía que el loco en cuestión salía de su morada, en un callejón cercano al colegio, para ofrecer a los niños algún señuelo para que se fueran con él. Seres categorizados como locos siguieron ocupando el turbulento imaginario infantil en los años 70-80, como un tal Rile en Sierra de Yeguas (Málaga), recordado como "hombre delgado y loco" que asustaba a los menores. Si no había ningún demente real, se creaba, o más típicamente se fabulaba para mezclar la realidad con lo fantástico. Así, en Villanueva de la Concepción (Málaga) se atemorizaba en los 80 a los críos con un Hombre loco, el cual — decían los rumores- se había escapado de la cárcel, y pululaba con ropas sucias por el pueblo, con el secreto objeto de secuestrar a algún niño.

Ninguno de ellos, a tenor de las entrevistas y las encuestas de las que disponemos, llegó a realizar las tropelías que los niños debían temer, especialmente el rapto, sin duda la estrella de las amenazas infantiles. Después de describir al loco en cuestión y ofrecer algún detalle de su aspecto o cotidianeidad, los informantes suelen reconocer que nunca se conoció "que verdaderamente hiciera algo malo". Era el caso también de otro Bartolo, un individuo malagueño de final del siglo, "alto, con grandes orejas y grandes gafas", el cual "vestía siempre con una camisa blanca y un pantalón largo y rajado", según nos recuerda una joven. Como en otros casos, el niño ve al loco en ocasiones, y recuerda dónde vivía o qué lugares frecuentaba, especialmente si estaba cerca del colegio. Así, de este Bartolo se recuerda que solía recaer en un bar cercano a la escuela. Y de Jaime, otro loco de Málaga coetáneo del anterior, que habitaba una vieja y enorme casa "justo delante del colegio", con lo que los niños podían presenciar sus desvaríos. Al parecer, el tal Jaime lucía una inmensa barba blanca y se presentaba estrafalariamente vestido de militar, con una boina y un palo, con el que amenazaba a la chiquillería. 
Los informantes suelen recordar a estos sujetos bajo la categoría de locos, tal y como aprendieron esa etiqueta en su niñez, aunque hoy traducen a la jerga de adulto: Bartolo era "una persona con trastornos psicológicos", Jaime "solo era una persona desequilibrada que en su momento me daba miedo". El miedo al loco parece ser una de las estrellas del imaginario infantil, y su fascinación va más allá de los asustadores paternos, pues las leyendas urbanas de locos figuran entre las preferidas por adolescentes y jóvenes, cuando se reúnen para "meterse miedo". Es el caso del loco asesino, llamado en algunos casos el loco psicópata o el loco del hacha, leyenda virtualmente extendida por toda España, protagonizada por un loco escapado del manicomio que decapita a un joven, golpeando con su cabeza el techo del coche, donde se refugia la novia de este (Pedrosa 2004: 213). Lejos de las ambigüedades de siglos pasados, el loco moderno, asociado al psicópata asesino, encarna el mal en estado puro, la violencia irracional, la sed de sangre, el enemigo por antonomasia; es metáfora del caos y de la ruina de la comunidad (Pedrosa 2007: 50-51). No se trata ya de que la monstruosidad sea un indicio de criminalidad, sino que el criminal es visto como un monstruo (Foucault 2001: 79).

Muchas veces los locos suscitan el terror por una peligrosidad basada en la violencia física. Eso explica que de algunos de ellos, los informantes recalquen su corpulencia. Así, el Cuervo era un hombre alto y fuerte que imponía terror a los niños de El Viso del Alcor (Sevilla), durante los años 60. Y en los 90, por poner otro ejemplo, es recordado en Torrox (Málaga) un tal Banasta, del que se resalta su "agresividad". Nuestro estudio evidencia que las madres alentaron este miedo con respecto a los locos varones. En menor medida el miedo infantil se encarna en una loca, aunque hay algún caso; en El Viso del Alcor la llamaban la Loca de la villa, y era "una mujer alta, seca", a quien los niños — sin duda influidos por los relatos de los adultos- recuerdan, en los años 50, "con un cuchillo en la mano que brillaba mucho". Los menores debían permanecer lejos del Pilar de la Muela, donde vivía la loca, a las afueras del pueblo. Este es uno de los rasgos de los locos: muchos viven en los márgenes de la localidad, tanto físicos como simbólicos. No son locos internados, sino que forman parte de la comunidad, aunque vivan en sus límites, fuera de lo seguro y conocido. En ocasiones encarnan la figura del salvaje, incivilizado, imprevisible. En la primera mitad del siglo XX, las madres de Osuna (Sevilla) asustaban a sus niños aludiendo a Manolito el Teta, un hombre que vivía solitario en una cueva, y "llevaba una chaqueta muy larga y un palo", amenazando a los niños con darles un trancazo. Más allá de la seguridad de lo conocido moran los seres monstruosos, u otros humanizados como ciertos personajes fantásticos andaluces: el Tío capaor que habitaría solitario en el campo de Archidona (Málaga) durante los 60-70; o la Mujer del Río rondando la ribera del Guadalquivir en Puente Genil (Córdoba) en la misma época. El peligro radica, a los ojos del niño, en que el foráneo, de vez en cuando, husmea por el pueblo o barrio. El loco se resiste a su absoluto aislamiento, y así puede sorprendernos en el momento más inesperado, como haría una demente inventada entonces por los padres en Sierra de Yeguas, la Loca Amparo, que los niños imaginaban — cuando oían algún ruido- que se acercaba arrastrando lastimeramente sus cadenas, fijadas a los tobillos. 


\section{VIEJOS, FEOS Y LISIADOS}

La categoría de monstruo existe en todas las culturas; es tan universal como el tabú del incesto o la familia, lo que pone de relieve una misma manera de identificar el miedo con aquello que es antagónico a lo humano, a lo natural, y que por ende no provoca solo el terror por su peligrosidad, sino también la aversión, el asco (Carroll 1987; Gilmore 2003). El monstruo es horrible, deforme, poderoso, violento, a menudo sádico, y no solo pone en pie nuestras peores pesadillas, sino también nuestra fantasía. El mismo sentimiento ambivalente de miedo y curiosidad, rechazo y fascinación, han despertado los humanos cuyos cuerpos presentaban deformidades y taras, ya que han sido susceptibles de ser considerados medio humanos, medio bestias. El estigma corporal, sea debido a una enfermedad como la lepra, sea por un nacimiento imperfecto como el que viene al mundo sin algún miembro o con alguno deforme, fue interpretado durante toda la Edad Media como un signo del mal, aunque también la corriente ascética del cristianismo aceptó la miserabilización del cuerpo hasta el punto de que el sufrimiento y el rechazo social constituían una vía de penitencia cuasisagrada. El ser horrible y monstruoso es impuro, incluso peligroso, pero también digno de lástima, dado que el propio Cristo (e infinidad de santos como Santo Domingo de Silos), convertido en sanador de cuerpos y almas, se ocupó de ciegos, cojos, lisiados, tullidos y contrahechos en general. Estos habrían de ser los elegidos en la otra vida, dado que practicaban la humildad y la penitencia por los pecados del mundo. Así, los seres incompletos, deformes, grotescos han sido objeto tanto de compasión, como de burla, lo que recreaba por ejemplo Victor Hugo con su Quasimodo.

En los siglos XVIII y XIX las premisas médicas sustituirán a las religiosas, y así los indicios de criminalidad y psicopatía seguirán buscándose en el cuerpo (como siglos atrás), si bien ya no como estigmas del maldito, sino como rasgos inherentes al malvado y perturbado. La criminología —a raíz de las teorías de Cesare Lombroso (18351909) - elevará a ciencia los paradigmas psiquiátricos sobre la inherente propensión a la maldad de ciertas personas con determinados rasgos físicos. Convertido en criminal, el monstruoso desafía al mismo tiempo dos leyes: la ley de los hombres (de la sociedad) y la ley de la naturaleza (Foucault 2001: 57). Transgrede simultáneamente los estándares de la apariencia, la salud, el pacto social y de lo que se considera natural.

Reformuladas, estas ideas no han desaparecido del todo de nuestro imaginario. El viejo calavérico es infrahumano porque está más cerca de la muerte que de la vida; el de aspecto horrible y el deforme tienen tanto de monstruo como de hombre. Ahí radica la fascinación. No es solo anómalo, sino por un lado contradictorio o paradójico, y por otro peligroso; une lo imposible a lo prohibido, como dice Foucault (2001: 58). Los niños no pueden evitar clavar su mirada en ellos, de la misma manera que durante años se exhibían como animales de feria. Goffman (1970) ha demostrado que la tara física es especialmente estigmatizable y atrayente, dado que como resulta imposible su ocultación, el sujeto se ve expuesto a la vez a la curiosidad y a la repulsa.

No extraña, por lo tanto, que entre los asustaniños andaluces de carne y hueso, encontremos tantos individuos cuya proclividad a inspirar terror es indisociable de su apariencia corporal anómala. En ocasiones la fealdad del individuo da pie al apodo, 
como el Feo Manana, un viejo que horrorizaba a los niños en los años 60 en Aguilar de la Frontera (Córdoba). La fealdad y la deformidad son también propiedad de muchos asustaniños ficticios, como el Hombre malo, el Estripaor (Destripador), el Coco Manolo o el Canco. Ciertas partes del cuerpo parecen ser especialmente propicias para suscitar el terror infantil. Así, los dientes. En Málaga se recuerda al Hombre de la dentadura, un viejo que asustaba a los críos mostrándoles sus dientes mondados durante los 80. Idéntico pánico despertaba en ese período el Tío de los dientes, otro anciano malagueño, aunque este de gran envergadura, el cual se sacaba su dentadura postiza para asustar a los niños, asemejándose así a un monstruoso devoraniños. El desdentado es, sin duda, uno de los arquetipos grotescos, y así no solo encontramos asustaniños reales, sino otros ficticios, como Tracañuelas, recordado como un ser alto, enjuto y sin dientes. El miedo a los desdentados no es independiente de ciertas creencias populares, como la que asegura que si uno sueña con que se le caen los dientes, significa que morirá pronto algún allegado o él mismo; "Soñar con dientes, muerte próxima de parientes", dice nuestro refranero. De la misma manera, es creencia en muchos lugares que los niños que nacen con dientes traen mala suerte o están malditos. En ambos casos, lo que atemoriza es lo anómalo: el adulto sin dientes, el niño dentado, son monstruos que atentan contra las leyes de la naturaleza, si bien lo raro, lo excepcional, claro está, también puede ser interpretado en clave positiva, y así el niño dentado puede ser visto como un prodigio, un ser dotado con cierta gracia divina o, simplemente, llamado a realizar grandes gestas.

Menos ambiguo es el viejo desdentado, ya que lo monstruoso deriva de lo decrépito, lo que está en el umbral de la muerte. En Málaga se recuerda en los años 90 a un viejo encorvado por décadas de duro trabajo en el campo, y agraciado para colmo con un ojo "malo", que suscitaba pánico entre los chiquillos, que le llamaban el Hombre de los gatos. A raíz de los informes que tenemos, el susodicho "siempre llevaba un saco al hombro, que se movía y se oían maullidos". No hay dudas de que el individuo en cuestión vivió realmente, pero ¿no estaría la percepción de los niños teñida de las connotaciones de alguno de los ficticios Hombres del saco que también "Conocían" por los relatos de sus madres? Imaginado como voraz comeniños, la mera presencia del Hombre de los gatos generaba la huida de los niños, pero también los más gallitos ponían a prueba su valor, desafiando al tullido anciano.

El Hombre de los gatos podría incluirse dentro de una subcategoría, la de los corcovados o jorobados, de larga tradición en el imaginario popular, como pudo comprobar Walter Starkie. El viajero y músico británico observó el trato dispensado a los jorobados en la Granada de los años 30 del siglo pasado, y concluye: "En los países meridionales un jorobado es siempre motivo de burla. En vez de inspirar compasión, la gente se ríe de él y le hace objeto de toda clase de invectivas" (Starkie 1985: 230). Sin embargo, el que recorriera Andalucía con su violín como un vagabundo, supo ver también que el corcovado era de alguna manera temido, ya que se le presuponían misteriosas capacidades como la de provocar el mal de ojo y "Volver fea y caduca a la mujer más hermosa del pueblo" (ibid.: 230). El lisiado ocupa, pues, un papel importante en los asustaniños. En ciertas leyendas urbanas, que aún hoy relatan los adolescentes, la cojera de una chica, de la cual se enamora perdidamente un joven, responde a que tiene una pata de cabra; el chico descubre que se ha acostado con el propio demonio, que desde antiguo se representa monstruosamente. 
BRUJAS

Uno de los rasgos físicos más frecuentes entre los asustaniños, tanto reales como ficticios, es su decrepitud, especialmente en los personajes femeninos, mayoritariamente horribles y repulsivas ancianas. En Osuna se recuerda el miedo que suscitaba en los chiquillos durante los años 60 Pepa la trapera, "una mujer mayor, gruesa, que vivía en una habitación de una casa de vecinos sola y siempre iba con muchas bolsas de trapos y cosas que encontraba en la basura". En realidad, no parece que la susodicha anciana tuviera ningún comportamiento hostil hacia los niños: "era una pobre mujer que estaba sola y que no sé de qué manera sobrevivía, pero no se metía con nadie". Sin embargo, ante cualquier desobediencia, las madres solían amenazar: «que viene Pepa la trapera!».

A menudo, los asustaniños femeninos encajan dentro de la categoría de bruja. Es cierto que la creencia en las brujas no ha gozado de tanto arraigo en Andalucía, como en otros lugares de la Península, especialmente la cornisa cantábrica, donde no es infrecuente que las madres aludan a ellas como asustaniños: "Miá que te come la guaxa" (Cabal 1983: 448). Pero tampoco en el sur está la bruja ausente del repertorio de asustaniños fantásticos. Como en ciertos cuentos, la cruel y grotesca bruja encerraría a los niños en una jaula para devorarlos a su antojo. En ocasiones no le falta la escoba, e invariablemente tiene un aspecto repulsivo: arrugada, cheposa, oculta tras un manto negro, luce una nariz larga, unos ojos saltones, y una cara llena de verrugas.

Influidas por esta imagen, se comprende que ciertas viejas enjutas y solitarias, conocidas en el pueblo o el barrio, se convirtieran en supuestas devoraniños. Parece que son las que fueron niñas quienes singularmente recuerdan a personajes femeninos horribles, como si fueran ellas las que más las hubieran temido. Una mujer de 74 años aún recuerda en su pueblo natal, La Lantejuela (Sevilla), a la Martirio, siempre "vestida de negro", con las ropas rotas, paseando con un perrito. Estas ancianas son tildadas a veces de locas. En los años 60-70 temían las niñas de Alcalá del Río (Sevilla) a una mujer canosa, vieja y andrajosa, que de vez en cuando veían por las calles del pueblo: la Cana.

El estudio de los asustaniños femeninos andaluces nos lleva a considerar dos cuestiones. En primer lugar, en el relato de los informantes andaluces, los personajes femeninos ficticios no difieren de los reales, como si unos y otros se retroalimentaran: no solo son horribles y arrugadas, sino que visten invariablemente de negro, de ahí que cualquier anciana de luto despertara en los niños el resquemor. Por otra parte, hay una diferencia llamativa en comparación con los asustaniños de otras latitudes. En Andalucía, la gran mayoría de estos personajes del miedo, tanto reales como ficticios, son masculinos. Incluso, en ocasiones, el personaje de la asustaniños se masculiniza, caso de una tal Mamen, que "vestida como un hombre", perseguía a los niños de Torrox durante los 90, armada con piedras. Los personajes femeninos no despiertan tanto el terror por su agresividad, sino por sus "malas artes", vinculadas a la hechicería. En Andalucía, dicha figura ha sido encarnada en ocasiones por la gitana. 


\section{GITANOS}

No extraña que los gitanos ocupen este papel en el imaginario popular, habida cuenta la secular desconfianza, cuando no directamente el rechazo que ha provocado este grupo étnico desde su entrada en la Península. Basta leer lo que les dedica Covarrubias en su Tesoro de la Lengua Castellana (1611): los gitanos son tildados de "gente perdida y vagabunda, inquieta, engañadora, embustidora" (Covarrubias 1995: 590). La creencia popular les hacía oriundos de Egipto (gitano = egipciano) y circulaba la leyenda de que se habían negado a albergar a la Sagrada Familia, cuando María y José huyeron a Egipto con Jesús, por lo cual habrían sido condenados eternamente a vagar por el mundo. Constituían, por lo tanto, no solo el extranjero, el otro, sino también el enemigo: una raza maldita. Si los hombres eran considerados ladrones, espías, prestidigitadores y volatineros, sus mujeres merecían un estigma suplementario: eran hechiceras y lascivas; rameras, como las considera, por ejemplo, Sancho de Moncada en 1619 (Esses 1994, III: 91).

El gitano se configuró como el arquetipo contrario a lo que con el tiempo hemos venido a considerar el buen ciudadano. Frente a los modales urbanos y civilizados, el gitano es salvaje, pues vive itinerante, errante, en los espacios de nadie; frente a las rutinas ordenadas, en especial las que confieren un oficio, el gitano ilustra el desorden, la indolencia, el ganarse la vida con lo que salga. Su supuesta vagancia y su fama de ladrones y embaucadores atenta contra los pilares de la ética del trabajo: honestidad, responsabilidad, disciplina. Incluso su tendencia grupal está en contra del individualismo imperante. Su peligrosidad radica en que se dice que no es de fiar: roba, engaña, miente. Sus mujeres son capaces de seducir y embaucar con artes de brujería, mientras que los varones serían pendencieros y ligeros para sacar la navaja y ajustar cuentas con ella. En el gitano se encarna, por lo tanto, no solo el vago y el ladrón, también el criminal.

La vinculación de la gitana como asustaniños es doble. Por un lado, tan antigua como su presencia en la Península es su fama de robaniños. En la Comedia llamada Medora, basada en La Cingana de Giancarli, Lope de Rueda retrata a una de estas gitanas raptoras de niños. Y recuérdese que Preciosa, la Gitanilla de Cervantes, no es más que una niña robada a una familia de procuradores por una gitana embaucadora, que la cría explotándola como bailadora. En los siglos XVIII y XIX los viajeros extranjeros se hacen eco del asentado estigma de las gitanas como robaniños. Este miedo ha tenido su plasmación en la lírica popular, como en esta nana, que se canta en pueblos de Sevilla, como Carmona o Alcalá de Guadaira (Fernández Gamero 2008: 199):

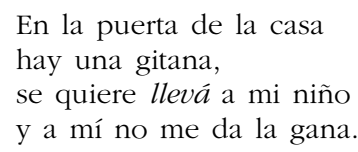

La gitana, además, es capaz de repudiar a sus propios hijos, como atestigua esta nana granadina, que recordaba García Lorca (1969: 104):

\footnotetext{
Este galapaguito

no tiene madre,

lo parió una gitana,

lo echó a la calle.
} 
Además de por su secular fama de raptaniños y repudianiños, la gitana sirvió para asustar a los menores por su vinculación con la hechicería, asociación que es tan antigua como su llegada a suelo peninsular. Gitanas, alcahuetas y quirománticas se servían de sus artes para engañar a los incautos, tal y como escribe el padre Martín del Río en el siglo XVI (Caro Baroja 1985: 2).

Frente a los asustaniños analizados hasta ahora, frecuentemente individualizados, los gitanos son evocados casi siempre de una manera difusa. En ocasiones, los informantes aluden a una gitana o gitano en concreto, pero por lo general recuerdan que se les asustaba con referencias genéricas: "a los niños que andan solos por la calle, les pillan los gitanos y se los llevan para siempre", recuerdan haber oído en Alcalá del Río. Cuando son identificados con algún individuo en concreto, no se sabe su nombre, porque nunca se mencionó, lo que es harto significativo: ontológicamente no son seres humanos iguales a "nosotros"; son "unos gitanos canasteros", "unos gitanos sucios y rateros, que paraban por el campo de mi abuelo", como indica una mujer de Morón (Sevilla) de 60 años, o unas "personas mal vestidas y descuidadas", tal y como los recuerda otra mujer de un cortijo de Osuna, con 73 años. La suciedad y el desaliño es la principal característica externa de estos gitanos, junto con el negro de su vestimenta. En alguna ocasión la vejez de la gitana le confiere un aspecto aún más brujeril. No se olvidan los informantes de otro de los rasgos estigmatizadores de los gitanos: su vida errabunda. Los gitanos asustaniños están "de paso", viven "en las carrozas" o "bajo un olivo", y en ocasiones habitan la más marginal e impura de todas las moradas: el basurero, el desecho de la civilización. Lo que temen los niños es, invariablemente, el secuestro, la separación de la seguridad del hogar y los padres. El peligro es constante, de noche y de día, en la calle o en el campo; el gitano y la gitana están siempre al acecho para, en un descuido de sus progenitores, atrapar violentamente al crío. En última instancia, pueden llegar a matarle.

Como en el caso de los locos, el adulto recuerda aquel miedo con cierta culpabilidad, al verse participando de un estigma que en la actualidad considera, mayoritariamente, infundado. Muchos informantes contraponen el miedo irracional a un peligro que reconocen hoy ficticio. Los gitanos son, ahora, "incomprendidos", y algún informante se lamenta de haber reproducido aquella imagen, "porque yo sabía que no era verdad". Sin embargo, perduran infinidad de chascarrillos, cuentos y leyendas en los que están involucrados los gitanos, y que los jóvenes y adultos relatan en diversas circunstancias. Uno de los más extendidos, ${ }^{7}$ habla del encuentro entre una mujer y una gitana clarividente, la cual percibe algo raro en el aura de aquella, por lo que le insta a que acuda "a echarse las cartas a su casa". La incrédula mujer rehúsa la proposición en principio, aunque decide entrar finalmente un día. En su lugar una vieja le da una carta, que la mujer prefiere sin embargo no abrir. Cuando ese mismo día muere atropellada por un camión, la policía encuentra en su bolsillo una nota que dice: "señora: le he echado las cartas. No salga usted de casa mañana porque morirá atropellada por un camión". Es una de esas leyendas urbanas, a las que muchos dan crédito. La gitana es aquí ambivalente, ya que sus poderes sobrenaturales no sirven para hacer el mal, aunque traen desgracia. Por otra parte, la leyenda aconseja tomar en serio las hechicerías de las gitanas.

\footnotetext{
${ }^{7}$ Lo hemos recogido en Sevilla, pero está divulgado por muchos otros lugares.
} 
Otras leyendas mezclan lo risible con el estigma de los que hasta hace poco vivían errantes por los caminos. Es célebre la historia del gitano que construyó un establo en el salón de su casa, leyenda cuyo origen se atribuye al barrio sevillano marginal conocido como las 3.000 viviendas, aunque hay quien asegura haber avistado burros en las casas de otros barrios de gitanos. Otras leyendas, muy del gusto de los adolescentes, mezclan el tópico del ajuste de cuentas con los fantasmas, y están extendidas en diferentes puntos de España:

En mi pueblo se dice que, una vez, hubo una pelea entre dos gitanos, en la que uno de ellos falleció en el acto debido a un golpe mortal que le propició el otro. Y, días después, se apareció el que había muerto con su misma cara, pero con distinto cuerpo, y mató al otro (Pedrosa 2004: 172).

Es posible que en los últimos tiempos el rumano haya ocupado el lugar secularmente atribuido al gitano. En ellos recae ahora la fama de ladrones, robaniños y traficantes de órganos infantiles. Estas leyendas no se transmiten solo oralmente, sino a través de Internet. En los últimos años, es frecuente que viajen por el espacio virtual bulos como el de los rumanos que venden unos perfumes con una droga que provoca la pérdida de consciencia del que la huele, lo que aprovechan para robarle "O quién sabe qué más". ${ }^{8}$ La historia se propaga con rapidez, dado que se insta a que se copie el mensaje y se envíe a familiares y amigos. Y así observamos cómo madres y abuelas atemorizan hoy a sus hijos y nietos con tal o cual "rumana mala", que ha tomado el lugar ocupado por la gitana.

\section{CONCLUSIONES}

En las encuestas y entrevistas se recuerdan no todos los asustaniños sino aquellos que dejaron huella, con lo que la galería de seres que aquí hemos analizado nos habla tanto de los arquetipos elegidos por los asustadores, como de los que verdaderamente suscitaron el miedo entre los infantes. Todos los asustaniños analizados son sujetos marginales, tomados por anormales y desviados; se ganan la vida con el robo, con la mendicidad, recogiendo cartones o, frecuentemente, no tienen oficio ni beneficio. Incluso los vendedores callejeros son parte de este mundo caracterizado por la inestabilidad, la sospecha, la inseguridad. No forman parte ni del sistema productivo legitimado, ni del sistema de valores hegemónico; mucho menos son sus prácticas convencionales. Constituyen, en conjunto, no solo lo diferente, sino lo anormal, lo desviado, a veces lo extraño, y por tanto, lo criticable y rechazable.

Su marginalidad es visible, bien por sus ropajes andrajosos o sus estrafalarios atuendos, bien porque el estigma está marcado en sus cuerpos: viejas decrépitas, lisiados, tuertos, feos de remate, casi monstruosos. El alejamiento o ignorancia de las prácticas de presentación en público, incluyendo el aseo, la prestancia, el andar, o los usos habituales en el trato, les sitúa en la esfera de lo incivilizado y lo animal. Son marginales también en el sentido físico: a menudo viven solos, en la calle, en cuevas, riberas, en el campo, en casas vetustas o semiderruidas, en los límites simbó-

\footnotetext{
${ }^{8}$ http://www.leyendasurbanas.com/article.php?story=20101107053416195 (consultado 10/03/15).
} 
licos de lo civilizado, ordenado y seguro. Algunos son los incorregibles de Foucault (2001: 59-60), resistentes a los intentos de rectificación de la conducta aplicados mediante las técnicas disciplinarias que la sociedad ordenada administra en instituciones como escuelas, lugares de trabajo e iglesia. En menor medida aparecen los monstruos (arquetipo más arcaico), si bien en el relato de los asustadores, unos y otros se entremezclan. No está presente, sin embargo, la tercera de las categorías de anormales, expuestas por Foucault: el masturbador, dado que este parte precisamente de una visión peligrosa y patológica de la sexualidad infantil. Es de destacar la ausencia absoluta de asustaniños sexuales (violadores, homosexuales, pederastas y prostitutas, que son más bien asustaadultos).

En conjunto, y salvo alguna excepción, los asustaniños analizados muestran más defectos que enfermedades o infracciones, es decir son anormales morales, más que patológicos o legales. Esta es, según Foucault, la tecnología de la anomalía humana (2001: 62) que surge modernamente, y que vigila y controla las "pequeñas anomalías, de personajes que son a la vez anormales y familiares" (ibid. 104). Dado que las conductas irregulares se consideran la antesala del crimen, al asustador le es fácil recurrir a historias truculentas, a leyendas, que en gran medida vinculan las fallas y debilidades morales a un supuesto deseo criminal.

Son evidentes los paralelismos entre los asustaniños reales y los ficticios, pero se observan diferencias. Aunque los asustaniños reales pueden ser iracundos y agresivos, estos se presentan en conjunto menos peligrosos y amenazantes que el Hombre del saco, el Canco, el Demonio o el Tío del trabuco. El secuestro es lo más temido, por encima de la muerte, reservada normalmente para los seres fantásticos, mucho más monstruosos. Además, aunque la agresión física es posible, el asustaniños real no es temido solamente por el potencial crimen, sino por la contaminación que entraña el contacto con el depravado. El recuerdo de los que sufrieron ese miedo revela tanto un discurso parento-infantil del miedo, que detecta el peligro, como un discurso de moralización que se opone a la perversión. El personaje señalado cumple además la función de encarnar al anómalo, al vicioso y temible: es un auténtico ejemplo, cercano, familiar, de la anormalidad humana.

En ocasiones, el asustaniños es el extraño, el extranjero: vagabundos, vendedores ambulantes, gitanos, fugitivos. Constituye virtualmente una práctica universal identificar el peligro con el otro, como ocurre en muchas leyendas (Díaz 2008). El otro no solo es diferente de nosotros, sino que no tiene el mismo estatus ontológico. Naturalmente, esos otros cambian con el tiempo. En el contexto de inmigración y de posterior crisis económica, resurge con fuerza el extranjero, encarnado en el rumano que trafica con órganos infantiles. En ese sentido, el cuadro de los asustaniños aquí analizados es un friso de los miedos, estigmas y marginalidades de la segunda mitad del siglo XX. Son anormales contemporáneos, y sin embargo, impregnados de imágenes y discursos arcaicos, que permanecen en estado latente durante siglos, y rebrotan periódicamente, a través de leyendas, cuentos, rumores o bulos informativos que hoy corren por Internet.

El poder establece lo deseable, legitimando sus estructuras, al identificar lo indeseable. Al señalar a los culpables, la sociedad justifica también las normas y convenciones que se apartan de aquellos. Junto al miedo, los asustadores intentaban suscitar también el repudio, el rechazo visceral, el asco en su sentido más sensitivo. Es 
necesario que el propio niño se autocontrole, y para ello se utiliza el arcaico instinto de preservación para no contaminarse, para no mancharse con aquello que es impuro, sucio. Como indicó Mary Douglas (2007), la suciedad simboliza el desorden, la anomalía, lo que está fuera de lugar, el límite o frontera que distingue lo puro de lo impuro. Las bases epistemológicas basadas en la semejanza-diferencia, orden-desorden, y otras dicotomías son puestas en cuestión simbólicamente por el anormal que así amenaza con el caos, dado que si se aceptara plenamente, no habría ya fundamento para la verdad, la identidad, la seguridad.

En los asustaniños reales, el anómalo no es siempre un otro distante, extraño, un extranjero. La galería de asustaniños reales pone de relieve que lo divergente también vive dentro, resaltando aquello que la comunidad normalmente oculta: la locura, la vejez, la miseria, la soledad, los pequeños vicios, en fin, de la cotidianeidad. Son miembros anormales de la sociedad, pero son miembros de ella. Por eso, tal vez, no reciben el absoluto repudio, dado que cuestionando con su presencia el orden, la pulcritud y la normatividad, nos recuerdan que nunca habremos extirpado el desorden, el caos, la fealdad de la vida, y aun la maldad dentro de nosotros mismos. A menudo el toxicómano, el loco, el tarado, la vieja, tienen todos su lugar en la comunidad. El pueblo, incluso el barrio, es su lugar, frente al anonimato de las ciudades, donde estos tipos encarnan más frecuentemente al extraño, al desconocido. A diferencia del modelo medieval (paradigmáticamente ejemplificado con el control político de la lepra), al apestado no se le excluye absolutamente; se le incluye, aunque reduciéndole a una categoría indeseable, como consecuencia de las tecnologías positivas de poder (Foucault 2001: 53), que incluyen un saber específico de normalización. Al extranjero se le puede expulsar, pero más difícilmente a quien es uno de nosotros. Esta es la ambivalencia del marginal en muchos casos. El que vive en los márgenes de la sociedad, la pone en peligro, al menos potencialmente, dado que los niños y jóvenes pueden conocerle, imitarle. Pero por otra parte, los marginales son necesarios, precisamente para enseñar a los niños los límites de lo infranqueable, los anti-ejemplos de hombres y mujeres.

Los asustaniños no solo revelan nuestros miedos; también nuestros tabúes, incluso nuestros sueños y aspiraciones. El vendedor ambulante no es de fiar pero ofrece una exótica mercancía; el vagabundo carece de los mínimos elementos del ciudadano, pero vive libre, recorriendo mundo y acumulando aventuras; el gitano es un ladrón pero, desde antiguo, se ensalza su libertad, de la misma manera que se destacan las dotes como bailaoras o la sensualidad de las gitanas; el bandolero, el ladrón, el que delinque es un sujeto temido, pero también se valora su arrojo, y en sus fechorías es posible ver el grito contestatario de las clases oprimidas que se rebelan así contra la injusta distribución de la riqueza; la bruja, la gitana, pueden robar o utilizar el mal de ojo, pero sus maravillosas capacidades pueden predecir el futuro, como también el corcovado, el ciego, el loco están dotados de dotes prodigiosas.

Lo que es extraño, raro, tabú despierta naturalmente la curiosidad y la fantasía; el ser excepcional atrae irremediablemente. El interés del niño por poner orden a lo que aparece como anómalo y desordenado, por conocer la verdadera naturaleza de estos individuos, se redoblará cuando adquiera el gusto por la aventura, y juegue a traspasar los límites de lo prohibido y oculto. La voz del peligro, que ha de mantener lejos al niño, es también seductora. Así es frecuente que los menores se diviertan provo- 
cando a estos seres antisociales, poniendo a prueba la veracidad de los relatos de los adultos. La exploración del miedo es una arcaica forma de aprendizaje, verificable en todos los cachorros de mamíferos. Con el desafío también se accionan los resortes que situarán a cada cual en su estatus, desde el más valiente al más miedica, a la par que se afirma la pertenencia del chico a su grupo de niños, la pandilla, forjada por la lealtad, la ayuda mutua y las experiencias emocionalmente intensas. Tarde o temprano el niño aprenderá a distinguir la ficción de la realidad. Sin embargo, es posible que, más allá de la función explícita (el control infantil a través del miedo), perdure la función latente, soterrada para siempre en el imaginario, dado que el uso como asustaniños de ciertas categorías de anormales revela el profundo descrédito de estos, o por lo menos la suspicacia, la sospecha, la aceptación de que hay algo oscuro, potencialmente peligroso, en estos tipos.

En torno a estos asustaniños reales encontramos, por lo tanto, antiguas y nuevas creencias, mezclándose la realidad con la ficción, el terror con la fascinación, los arquetipos mitológicos del miedo con la experiencia directa. Acaso esa mezcolanza sea también la responsable de que los asustaniños reales hayan suscitado unos ambivalentes sentimientos, que aún hoy cabe inferir en los recuerdos de los que temieron y rieron con estos individuos anormales.

\section{BIBLIOGRAFÍA CITADA}

Bajtin, Mijail. 1995. La cultura popular en la Edad Media y en el Renacimiento. El contexto de François Rabelais. Madrid: Alianza Universidad.

Berger, Peter y Thomas Luckmann. 1968. La construcción social de la realidad. Buenos Aires: Amorrortu.

Cabal, Constantino. 1983. La mitología asturiana. Oviedo: Idea.

Cantero, Pedro. 2003. "Hombrear. Modos de aprender a ser hombre", en Juan Blanco y José María Valcuende (eds.), Hombres. La construcción cultural de las masculinidades: 53-65. Madrid: Talasa.

Caro Baroja, Julio. 1985: "Prólogo: los gitanos en la literatura española”, en J.-P. Clébert, Los gitanos: 7-26. Barcelona: Orbis.

Caro Baroja, Julio. 1990. Ensayo sobre la Literatura de Cordel. Madrid: Istmo.

Carroll, Noel. 1987. "The Nature of Horror". The Journal of Aesthetics and Art Criticism 46(1): 51-59. doi: $10.2307 / 431308$.

Covarrubias, Sebastián de. 1995. Tesoro de la Lengua Castellana o Española. Madrid: Castalia.

Del Campo, Alberto. 2008. "Hacer el loco. Muerte, miedo y subversión en torno a la Navidad". VI Jornadas de Protección del Patrimonio Histórico de Écija: 103-143. Écija: Asociación de Amigos de Écija.

Del Campo, Alberto y Rafael Cáceres. 2013. Historia cultural del flamenco. El barbero y la guitarra. Córdoba: Almuzara.

Di Pinto, Elena. 2005. La tradición escarramanesca en el teatro del Siglo de Oro. Madrid: Iberoamericana-Vervuert.

Díaz Viana, Luis. 2008. Leyendas populares de España: Históricas, maravillosas y contemporáneas. Madrid: La Esfera de los Libros.

Douglas, Mary. 2007. Pureza y peligro. Un análisis de los conceptos de contaminación y tabú. Buenos Aires: Nueva Visión.

Esses, Maurice. 1992-1994. Dance and Instrumental Diferencias in Spain during the 17th and early 18th centuries. 3 vols. Nueva York: Pendragon Press.

Fernández, Julio y Virginia Isla. 2012. "La atracción del vino en los viajeros europeos de los siglos XVIII y XIX.. Poligonos. Revista de Geografía 23: 235-262. doi: 10.18002/pol.v0i23.542. 
Fernández Gamero, Manuel. 2008. La rosa de los rosales. Estudios sobre las canciones de cuna en Andalucía. Sevilla: Diputación de Sevilla.

Fontaine, Laurence. 1993. Histoire du colportage en Europe (XVe-XIXe siècle). París: Albin Michel.

Foucault, Michel. 1967. Historia de la locura en la época clásica. 2 vols. México: FCE.

Foucault, Michel. 1978. Microfísica del poder. Madrid: Las Ediciones de la Piqueta.

Foucault, Michel. 2001. Los anormales. Madrid: Akal.

García Lorca, Federico. 1969. "Las nanas infantiles", en F. García Lorca, Obras completas. Madrid: Aguilar.

Gilmore, David. 2003. Monsters. Evil Beings, Mythical Beasts, and All Manner of Imaginary Terrors. Philadelphia: University of Pennsylvania Press.

Goffman, Erving. 1970. Estigma. La identidad deteriorada. Buenos Aires: Amorrortu.

Hijano, Manuel, Carmen Lasso y Fernando C. Ruiz. 2011. "Figuras del miedo en la infancia: el hombre del saco, el sacamantecas y otros asustachicos". Fuentes 11: 175-194.

Kowalewski, M. 1988. "Double stigma and boundary maintenance: How gay men deal with AIDS". Journal of Contemporary Ethnography 17(2): 211-228. doi: 10.1177/089124188017002004.

Mitre, Emilio. 2004. Fantasmas de la sociedad medieval. Enfermedad. Peste. Muerte. Valladolid: Universidad de Valladolid.

Pedrosa, José M. 2004. La autopista fantasma y otras leyendas urbanas españolas. Madrid: Páginas de Espuma.

Pedrosa, José M. 2007. "Carreteras peligrosas y locos que cortan cabezas: de un cuento en sánscrito del siglo XII a la leyenda urbana de La muerte del novion. Signa. Revista de la Asociación Española de Semiótica 16: 35-55.

Pérez Köhler, Alejandro. 2006. "Consideraciones jurídicas sobre el Romance de El Pernales". Anuario de la Facultad de Derecho 2005/6: 206-228.

Rose, Hugh James. 2012. Viaje a la Andalucía inexplorada. Bosquejos sobre la vida y el carácter de los españoles del interior. Sevilla: Centro de Estudios Andaluces-Renacimiento.

Santos, Adolfo y Alfonso Blanco. 1996. Infancias bajo el cielo azul de Sevilla. Sevilla: Caja San Fernando.

Starkie, Walter. 1985. Don Gitano. Granada: Diputación Provincial de Granada.

Fecha de recepción: 9 de junio de 2015

Fecha de aprobación: 27 de septiembre de 2015 